\title{
Comparison of fish catches from a buoyant pop net and a beach seine net in a shallow seagrass habitat
}

\author{
Rod M. Connolly \\ Department oi Zoology, University of Adelaide, South Australia 5005, Australia
}

\begin{abstract}
A large $\left(25 \mathrm{~m}^{2}\right)$, remote-release buoyant pop net, floorless to permit normal behaviour by benthic fish, and a beach seine net were evaluated by comparing the catch from the 2 net types. Both nets were made of $1 \mathrm{~mm}$ mesh, aimed at catching fish from 10 to $100 \mathrm{~mm}$ long. The pop net caught more fish than the seine net, mainly because 9 times more Favonigobius lateralis were caught in the pop net. Apart from species such as $F$. lateralis that dwell on the sea bed, the seine net catches small fish as well as the pop net, and for some species is a faster, cheaper collection method for survey work. However, as seine net catches can misinform about rank order of abundances of species, its main use may be in collecting presence/absence data. The pop net gives a more accurate estimate of bottom-dwelling species, and is useful where fish need to be collected from small, defined areas such as experimental plots
\end{abstract}

KEY WORDS: Fish - Zostera - Macrofauna - Sillaginodes punctata $\cdot$ Recruitment

Seagrass meadows provide important habitat for small fish (Pollard 1984) and most ecological studies of seagrass fauna include estimates of fish densities. Methods used to count fish include netting, poisoning and visual surveys. The composition of fish assemblages reported depends on the method of collection. Assemblages collected from the same meadow using 2 different methods (poisoning and trawling) can be more different than assemblages collected from different meadows with the same method (Gray \& Bell 1986). Even the catches from different types of beam trawl from within one seagrass meadow vary in number of species and number of individuals (McNeill \& Bell 1992).

Fish assemblages in eelgrass Zostera muelleri Irsmisch ex Aschers. meadows in shallow South Australian embayments have been surveyed using a small, fine mesh beach seine (Connolly in press). Data from seine netting is more informative when an estimate can be made of the catching efficiency of the net (Parsley et al.
1989), and to do this, a buoyant pop net was designed with the aim of making a more complete catch. The seine net is also unwieldy when fish need to be collected from small, defined areas. The pop net permits collection of fish from such areas, for example from experimental plots in which habitat has been manipulated.

Buoyant pop nets usually consist of 4 mesh walls, depressed prior to release, and a mesh floor. Such traps can be lifted clear of the water to collect ensnared fish. Small pop nets (area $5.6 \mathrm{~m}^{2}$ ) have been used in vegetated backwaters of a river (Dewey et al. 1989) while a larger net $\left(14.5 \mathrm{~m}^{2}\right)$ was tested for estimating fish abundance associated with artificial structures in lakes (Larson et al. 1986). In the present study, a floorless pop net was designed with the same intention as the much smaller floorless net of Dewey et al. (1989); viz. to avoid the problem that any floor of mesh fine enough to catch the target fish $(10$ to $100 \mathrm{~mm}$ length in the present study) would alter the nature of the sea bed and might disrupt the feeding behaviour of benthic fish. The pop net is an alternative to the floorless lift net designed to collect fish from littoral marshes (Rozas 1992). The pop net design nets 4 times the area of the lift net and avoids the need for above-ground structures used to raise the net. This absence of aboveground structures may be especially important in more open, less densely vegetated habitats.

This paper compares fish catches from the pop net and seine net in shallow eelgrass meadows to determine the relative catching efficiencies of the 2 methods.

Materials and methods. The experiment was done in November 1991 on Torrens Island in the Barker Inlet - Port River estuary, South Australia. This shallow, marine-dominated estuary contains large intertidal flats (maximum tidal amplitude $2 \mathrm{~m}$ ) supporting eelgrass Zostera muelleri, typically with a canopy height of 10 to $20 \mathrm{~cm}$. Netting was done during the day on an incoming tide, at water depths between 40 and 
$100 \mathrm{~cm}$. Sites were positioned at random along a $1 \mathrm{~km}$ stretch of coast and at each site both a pop and seine net were used simultaneously within $40 \mathrm{~m}$ of one another. The order of netting was chosen randomly. The aim was to compare the catch of the 2 methods. The assumption was made that with this experimental design, different catch rates would reflect different catching efficiencies of the net types.

The seine net used was $5 \mathrm{~m}$ long by $2 \mathrm{~m}$ high, of $1 \mathrm{~mm}$ diameter fibreglass mesh, and was weighted along the bottom with floats at the top. The net was pulled by 2 people, one at either end, for (a premeasured) $20 \mathrm{~m}$; the actual area netted was calculated over 10 pulls to be $84 \mathrm{~m}^{2}$ ( $\mathrm{SE}=1.19$ ).

The pop net consisted of 4 walls of the same material and mesh size used in the seine net, and was $5 \mathrm{~m}$ long by $1.4 \mathrm{~m}$ high (Fig. 1). The top of the mesh was sewn around lengths of $25 \mathrm{~mm}$ diameter PVC pipe, sealed at the ends for buoyancy. The bottom was weighted, and also pegged to the sea bed. The net was set at low tide when the sea bed was exposed. The netting was folded and sandwiched between the sea bed and the PVC pipe, which was pushed down so as to make the whole apparatus as nearly as possible flush with the sea bed. The top of the net was weighted with 8 flat concrete blocks of $10 \mathrm{~kg}$ each, so that when the net was covered with water it did not move until released. Each concrete block was attached by wire along the sea bed to 1 of 2 remote points, at least $10 \mathrm{~m}$ from the net. The net
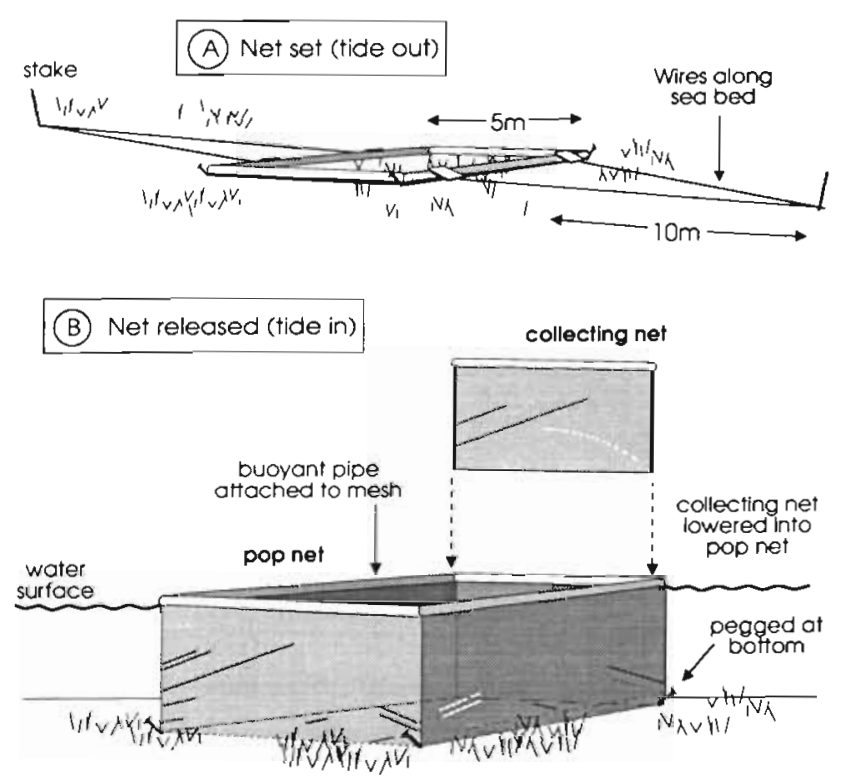

Fig. 1. Pop net design (a) Prior to release (diagram is representative only - actual number of blocks used was 8,4 from each of the 2 stakes, which were situated diagonally to the net so that all sides received 2 blocks). (b) After release, with collecting net remained in place for $1 \mathrm{~d}$, being released on the following day's incoming tide. At release, 1 person moved slowly to each of the 2 remote points, and all blocks were simultaneously pulled away from the net. The top of the net surfaced within 2 seconds of release in water up to $1 \mathrm{~m}$ deep. The area netted was $25 \mathrm{~m}^{2}$.

A solid-framed collecting net (Fig. 1), of the same mesh, was used to collect fish from within the pop net. The collecting net, which fits neatly inside the pop net, was pulled 3 times through the area with the pop net walls being held against the ends of the collecting net at all times. Fish were collected separately from each pull. This method removes fish immediately after net release, unlike the method of Rozas (1992) in which fish are collected in a pit on the receding tide. Although predation within nets was not reported as a problem in the densely vegetated marshes in which Rozas (1992) worked, predation by decapods, birds or other fish could result in losses on open eelgrass flats, and collecting fish immediately avoids this potential problem. The pursing together of the mesh sides to collect fish (Dewey et al. 1989), whilst useful for small nets, is not manageable over $25 \mathrm{~m}^{2}$.

All fish were identified and the first 50 of each species from each pull of the seine net or the collecting net were measured. Lengths of individuals of common species were compared from the 2 net types by calculating a mean length for individuals within a net and testing differences over all nets using a paired $t$-test.

Recovery efficiency within pop nets was estimated using the method of Kneib (1991). Numbers from the 3 pulls of the collecting net tended to describe an exponential decay function, and a linear regression through the 3 points (using $\log _{10}$ transformed values of number of fish and number of pulls) predicted the number of pulls needed to remove all fish from the pop net. The total number of fish within the pop net was estimated by summing the predicted number of fish from all pulls. Efficiency was calculated as the proportion of the estimated total number of fish actually caught in each of the 3 pulls, counted cumulatively. For total fish numbers and long-finned goby Favonigobius lateralis (Macleay) numbers this procedure was done separately for each pop net. Individuals of King George whiting Sillaginodes punctata (Cuvier \& Valenciennes) and smallmouthed hardyhead Atherinosoma microstoma Günther were uncommon in the second and third pulls of collecting nets, and Kneib's (1991) method was used on data averaged over all pop nets. The precision of the recovery efficiency value could therefore not be estimated for these 2 species. When the method was used on total fish and $F$. lateralis numbers summed over all pop nets, however, estimates of recovery efficiency were similar to the means of values from separate pop nets. This suggests that the recovery efficiencies esti- 
mated for $S$. punctata and $A$. microstoma are reliable. No A. microstoma were caught in the third pull of collecting nets in any pop net, so the regression for this species was calculated on $\log _{10}(x+0.1)$ data. This procedure would tend to underestimate recovery efficiency.

Prior to the main experiment, 4 paired nettings were done on the same stretch of coast and the numbers of fish per $\mathrm{m}^{2}$ (all species combined) were counted (Table 1). The estimate of the variability of differences (within pairs) between pop net and seine net catches was used to estimate the sample size required to attain desired probabilities of type I and II statistical errors for a specified effect size. I wanted a good chance of detecting a difference when seine net catches differed from pop net catches by more than $20 \%$. The consequences of the 2 error types were considered equally serious, implying $\alpha=\beta$. Taking into account the cost and effort involved in using pop nets and the high variability of fish densities, I believe that $\alpha=\beta=0.05$ is appropriate. For an effect size of 0.76 fish $\mathrm{m}^{-2}$ (i.e. $20 \%$ of 3.80 , the mean catch of the pop net in Table 1), using Eq. (8.8) in Zar (1984) for a paired $t$-test, the required number of pairs is 17 or more.

Seventeen pairs were therefore used in the main comparison. After checking the normality of the distribution of differences using Lilliefors' (1967) test, data were analysed using a paired t-test. Although it was considered unlikely that the catch rate of the pop net would be lower than that of the seine net, a 2 -tailed test was used so as not to preclude the possibility of testing the significance of any departure in that direction.

To determine why the effectiveness of the 2 net types might be different, underwater observations were made of fish behaviour before and after pop net release and from behind the seine net during seine netting.

Results. A total of 4991 fish of 15 species were counted during the study (Table 2). The number of fish caught in pop nets was significantly greater than that from seine nets (Table 3). Analysis of the more common species shows that the higher number of fish in pop nets reflects catches of the most common species, Favonigobius lateralis, which was caught much more often in pop nets (Table 3). Numbers of Sillaginodes punctata and Atherinosoma microstoma were not
Table 1 Results of preliminary study. Total fish numbers (ind. $\mathrm{m}^{-2}$ ). $\mathrm{n}=4$ pairs of nets

\begin{tabular}{|lcc|}
\hline & Mean & SD \\
\hline Pop net & 3.80 & \\
Seine net & 1.70 & \\
Differences & 2.10 & 0.80 \\
\hline
\end{tabular}

shown to be different from the 2 net types. In the case of these 2 species, the statistical power of the tests was low. The chance of detecting a difference in seine and pop net catches of $20 \%$ of the mean pop net catch was $12 \%$ for S. punctata and $7 \%$ for A. microstoma.

Numbers of blue sprats Spratelloides robustus Ogilby provide no meaningful comparison of net types because all fish were caught in 1 seine pull. A total of only 10 bridled goby Arenigobius bifrenatus Kner. were caught during the study, but all of these were from pop nets, with individuals found at 4 different sites. The lack of any $A$. bifrenatus in seine catches, despite the area netted by seine nets being more than 3 times that netted by pop nets, is notable.

No significant differences were found in the lengths of fish from pop and seine nets for any of the 3 common species, Sillaginodes punctata, Favonigobius lateralis and Atherinosoma microstoma (Table 4). Numerous spat of A. microstoma (length 7 to $20 \mathrm{~mm}$ ) were collected in several pop nets but were rarer in seine nets.

The proportion of fish in pop nets caught by each successive pull of the collecting net declined rapidly

Table 2. Number of individuals of main species caught during study. Pop net and seine net combined

\begin{tabular}{|lcc|}
\hline & No. of fish & $\%$ of total \\
\hline Favonigobius lateralis & 3209 & 64.3 \\
Sillaginodes punctata & 1233 & 24.7 \\
Atherinosoma microstoma & 217 & 4.4 \\
Spratelloides robustus & $167^{\mathrm{a}}$ & 3.3 \\
Other species & 165 & 3.3 \\
All species total & 4991 & 100 \\
aAll caught in 1 seine net & & \\
\hline
\end{tabular}

Table 3. Comparisons of pop net and seine net catches. Numbers in first 3 columns are means of 17 sites (fish $\mathrm{m}^{-2}$ ). For differences, pop net catch is greater than seine net except where difference is negative. 17 pairs used in $t$-tests

\begin{tabular}{|lccrrr|}
\hline & Pop net & Seine net & $\begin{array}{c}\text { Paired } \\
\text { differences }\end{array}$ & $\begin{array}{r}\text { Difference } \\
\text { as of pop }\end{array}$ & $\begin{array}{c}\text { Probability } \\
\text { from } t \text {-test }\end{array}$ \\
\hline All species & 6.318 & 1.615 & 4.703 & 74 & $<0.001$ \\
Favonigobius lateralis & 5.414 & 0.636 & 4.778 & 88 & $<0.001$ \\
Sillaginodes punctata & 0.584 & 0.690 & -0.106 & -18 & 0.462 \\
Atherinosoma microstoma & 0.125 & 0.080 & 0.045 & 36 & 0.423 \\
\hline
\end{tabular}


Table 4. Comparison of lengths of fish from pop net and seine net. Numbers are means (in $\mathrm{mm}$ ) from all nets of the mean length of fish within a net. Differences were tested with a paired t-test, using only pairs of nets in which at least 1 individual of the species was caught in both net types (this figure in column 'No. of pairs')

\begin{tabular}{|lcccc|}
\hline & Pop net & Seine net & No. of pairs & Probability from t-test \\
\hline Favonigobius lateralis & 28.58 & 29.54 & 17 & 0.109 \\
Sillaginodes punctata & 30.56 & 30.55 & 16 & 0.993 \\
Atherinosoma microstoma & 32.85 & 41.64 & 12 & 0.178 \\
\hline
\end{tabular}

for all species combined and for the common species (Table 5). Note, however, that the decline in the proportion of Favonigobius lateralis caught in successive nets was less steep than for Sillaginodes punctata and Atherinosoma microstoma. Recovery efficiencies were very high for $S$. punctata and A. microstoma, with virtually all $S$. punctata and all A. microstoma recovered by the third pull. Recovery efficiencies for $F$. lateralis, and since this was the most abundant species therefore also for all species combined, were lower (Table 5).

Underwater observations of pop nets gave no evidence of fish being more common around the net or blocks prior to release. Favonigobius lateralis and juvenile Sillaginodes punctata usually swam alone but sometimes showed weak schooling behaviour. F. lateralis always remained on the sea bed, while juvenile S. punctata tended to swim just over the top of the eelgrass canopy. Atherinosoma microstoma schooled strongly and swam near the water surface.

After net release, but prior to use of the collecting net, individuals of the above 3 species behaved as if they were not aware of being trapped, and swam within the $25 \mathrm{~m}^{2}$ confine. Larger fish, such as adult smooth toadfish Torquigener glaber (Freminville) (up to $70 \mathrm{~mm}$ long), > 1 yr old yelloweye mullet Aldrichetta forsteri (Valenciennes) (to $80 \mathrm{~mm}$ ), and >1 yr old sea garfish Hyporhamphus melanochir (Valenciennes) (to $130 \mathrm{~mm}$ ) were uncommon, but sometimes swam around the edge of the enclosure.
When trapped in a small volume of water at the end of a collecting net pull, Sillaginodes punctata and Atherinosoma microstoma were observed swimming near the surface, whereas Favonigobius lateralis remained near the sea bed.

Observers of seine nets saw some larger, fast swimming fish (unidentified) swim out of the ends of the net. Smaller schooling fish such as Atherinosoma microstoma sometimes swam along in front of the net, but were caught as the net-pullers moved together at the end of a run, closing off any escape. Observations of fish in vegetated habitats in shallow water are, of course, not quantitative, but no fish were seen escaping under the net.

Discussion. The pop net caught more fish than the seine net, mainly because 9 times more Favonigobius lateralis were caught in the pop net. F. lateralis individuals remained on the sea bed at all times, and not only avoided capture by the seine but also had a lower recovery efficiency within the pop net than other common species. Although no $F$. lateralis were seen escaping under the seine, this is the most likely place of escape, as small fish could fit into the shallow depressions in the sea bed over which the bottom rope of the seine would pass. Observations of the seine being used in meadows of seagrass species having a more erect habit (e.g. Posidonia australis Hook.) have clearly shown that small, bottom-dwelling fish do escape under the net, which glides through the sea-

Table 5. Comparisons of catches from 3 pulls of collecting net in pop nets. E\% = recovery efficiency, calculated as described in text (numbers are means, with standard errors in parentheses; no estimates of precision are possible for $S$. punctata and A. microstoma). $\mathrm{C} \%=$ percentage of total pop net catch caught in collecting net (calculated as $\%$ of total catch of individual pop net; means shown)

\begin{tabular}{|c|c|c|c|c|c|c|}
\hline & \multicolumn{2}{|c|}{ Pull 1} & \multicolumn{2}{|c|}{ Pull 2} & \multicolumn{2}{|c|}{ Pull 3} \\
\hline & $E \%$ & $\mathrm{C} \%$ & $E \%$ & $\mathrm{C} \%$ & $E \%$ & $\mathrm{C} \%$ \\
\hline All species & $\begin{array}{l}50.1 \\
(7.6)\end{array}$ & 61.1 & $\begin{array}{l}61.8 \\
(7.9)\end{array}$ & 24.9 & $\begin{array}{l}67.8 \\
(7.6)\end{array}$ & 14.0 \\
\hline Favonigobius lateralis & $\begin{array}{l}50.0 \\
(9.0)\end{array}$ & 56.8 & $\begin{array}{l}60.3 \\
(9.2)\end{array}$ & 27.4 & $\begin{array}{l}65.3 \\
(9.0)\end{array}$ & 15.8 \\
\hline Sillaginodes punctata & 83.3 & 88.6 & 95.2 & 5.9 & 98.8 & 5.5 \\
\hline Atherinosoma microstoma & 99.1 & 97.9 & 100 & 2.1 & 100 & 0 \\
\hline
\end{tabular}


grass but not actually along the sea bed. During the testing of a beach seine net in a reservoir, fish species known to be associated with the bottom escaped more often over coarse sediment, presumably by getting under the net via irregularities in the bottom (Parsley et al. 1989). The possibility remains that F. lateralis is actually attracted to the pop net area, perhaps towards extra feeding opportunities provided by the disturbance of sediment whilst setting the net, violating the assumption that approximately equal numbers of fish would be in the vicinity of both net types. However, the evidence against this possibility is that observers did not detect any increased abundance of $F$. lateralis near the net prior to release, and that $F$. lateralis, even when trapped within the pop net, avoided the collecting net more often than the other common species. Arenigobius bifrenatus, which is also intimately associated with the sea bed and at times even burrows in the sediment, also seemed to avoid capture by the seine net.

Sillaginodes punctata, which swims mid water, seems to be caught equally well by both net types. Furthermore, most of the individuals of this species were caught in the first pull of the collecting net within the pop net. The numbers of Atherinosoma microstoma, which swims near the water surface, were also not shown to be different from the 2 net types, and very nearly all of the individuals of this species were caught in the first pull of the collecting net. Although no significant difference was shown in the mean length of A. microstoma from pop and seine nets, observations indicate that the seine net may catch $A$. microstoma spat less effectively than the pop net.

For general survey work in shallow embayments the seine net, which is much faster and cheaper to use than the pop net, can be considered a relatively accurate method for collecting small fish other than species that remain intimately associated with the sea bed (and possibly also spat less than $20 \mathrm{~mm}$ long). The seine net would also be useful for comparing numbers of a single species, such as Sillaginodes punctata, from different locations. Since data from the seine net can misinform about the rank order of abundances of species, those data are most reliably treated as presence/absence data for surveys of fish assemblages.

Most areas of eelgrass in South Australia are emergent or nearly so at low tide, permitting use of the pop net. Where there is particular interest in species that are not well caught by the seine, or where accurate collection of fish from relatively small, defined areas is required, the pop net described in this paper is a useful new design. The pop net, as presented here, would also be useful subtidally for the collection of fish species that remain within the seagrass canopy when disturbed. The relatively unsophisticated release mechanism was designed to be robust in fast flowing water which sometimes carries large quantities of drift algae. It also overcomes most of the problems caused by anglers (Larson et al. 1986), and during this study all net releases were successful. The range of recovery efficiencies within pop nets from $65 \%$ for Favonigobius lateralis to $100 \%$ for Atherinosoma microstoma approximately matches that for fish in Rozas' (1992) lift net. The main advantage of the pop net presented here is that it collects fish from larger areas than most other designs without losing portability. Kneib's (1991) flume weir collects fish reliably from an even larger area $\left(100 \mathrm{~m}^{2}\right)$ but is best used for repeated sampling of the same site. The method of fish retrieval from the pop net worked well in eelgrass, but would be less effective in taller, more robust vegetation, where the collecting pits of Rozas (1992) would be more effective.

Acknowledgements. I thank Dr Alan Butler for guidance, Dr Christine Campbell and an anonymous referee for comments on the manuscript, Andrew Melville for invaluable field support, and Barry Bruce for the seine net design. South Australian Department of Fisheries and the Mark Mitchell Foundation assisted with the purchase of net materials. This work was done while I was supported by an Australian Postgraduate Research award.

\section{LITERATURE CITED}

Connolly, R. M. (in press). A comparison of fish assemblages from seagrass and unvegetated areas of a southern Australian estuary. Aust. J. mar. Freshwat. Res. 45

Dewey, M. R., Holland-Bartels, L. E., Zigler, S. J. (1989). Comparison of fish catches with buoyant pop nets and seines in vegetated and nonvegetated habitats. N. Am. J. Fish. Man. 9: 249-253

Gray, C. A., Bell, J. D. (1986). Consequences of two common techniques for sampling vagile macrofauna associated with the seagrass Zostera capricomi. Mar. Ecol. Prog. Ser. 28: $43-48$

Kneib, R. T. (1991). Flume weir for quantitative collection of nekton from vegetated intertidal habitats. Mar. Ecol. Prog. Ser 75: 29-38

Larson, E. W., Johnson, D. L., Lynch, W. E. (1986). A buoyant pop net for accurately sampling fish at artificial habitat structures. Trans. Am. Fish. Soc. 115: 351-355

Lilliefors, H.W. (1967). On the Kolmogorov-Smirnov test for normality with mean and variance unknown. J. Am. Stat. Ass. 62: 399-402

McNeill, S. E., Bell, J. D. (1992). Comparison of beam trawls for sampling macrofauna of Posidonia seagrass. Estuaries 15: $360-367$

Parsley, M. J., Palmer, D. E., Burkhardt, R. W. (1989). Variation in capture efficiency of a beach seine for small fishes. N. Am. J. Fish. Man. 9: 239-244

Pollard, D. A. (1984). A review of ecological studies on seagrass-fish communities, with particular reference to recent studies in Australia. Aquat. Bot. 18: 3-42

Rozas, L. P. (1992). Bottomless lift net for quantitatively sampling nekton on intertidal marshes. Mar. Ecol. Prog. Ser. 89: 287-292

Zar, J. H. (1984). Biostatistical analysis, 2nd edn. PrenticeHall, Englewood Cliffs, NJ

Manuscript first received: November 8, 1993

Revised version accepted: March 24, 1994 